\title{
Ensinar português em Timor-Leste: relatos e reflexões
}

\section{Teaching Portuguese in East Timor: testimonials and reflections}

\author{
Regina Helena Pires de Brito* \\ Alexandre Marcelo Bueno**
}

\section{RESUMO}

Este trabalho apresenta, na primeira parte, duas experiências de ensino da língua portuguesa em Timor-Leste. Separadas pelo tempo, cada relato mostra diferentes problemas e distintas situações a partir das necessidades sociais, culturais e históricas da língua portuguesa em Timor-Leste. Na segunda parte, apresentase uma reflexão conjunta a respeito da formação de professores em Timor-Leste e, principalmente, uma defesa da necessidade de se conhecer as particularidades locais a partir de pesquisas de campo e de relatos das vivências dos profissionais que trabalham em projetos de cooperação internacional para se planejar adequadamente o ensino formativo e incentivar uma política de educação linguística mais efetiva.

Palavras-chave: Timor-Leste; Ensino de língua portuguesa; Contexto Multilinguístico.

Recebido em 26 de setembro de 2020.

Aceito em 12 de novembro de 2020.

DOI: http://doi.org/10.18364/rc.2022n62.478

\footnotetext{
* Universidade Presbiteriana Mackenzie, reginahelena.brito@mackenzie.br, http://orcid.org/0000-0002-0634-8572

** Universidade Presbiteriana Mackenzie, alexandrembueno@gmail.com, http://orcid.org/0000-0002-0798-3615
} 


\section{ABSTRACT}

This work presents, in the first part, two experiences of Portuguese language teaching in Timor-Leste. Separated by time, each case shows different problems and different situations from the social, cultural, and historical necessities of the Portuguese language in Timor-Leste. In the second part, there is a reflection on the formation of teachers in East Timor and, mainly, a defence of the need to know the local particularities from field research and accounts of the experiences of professionals working in international cooperation projects in order to adequately plan formative teaching and encourage a more effective language education policy.

Keywords: East Timor; Portuguese language teaching; Multilinguistic Context.

\section{Breve histórico da presença portuguesa em Timor-Leste}

A história da presença portuguesa em Timor-Leste é bastante longa ${ }^{1}$. Pela historiografia oficial, os portugueses chegaram à ilha de Timor no ano de 1512. Desde então, Timor-Leste passou a fazer parte do império lusitano durante o período colonial, fornecendo sândalo (madeira aromática típica do sudeste asiático) entre outros produtos primários².

Não houve efetivamente grandes esforços portugueses, durante os quatro séculos de colonização, no sentido de desenvolver Timor-Leste em seus diferentes aspectos sociais, econômicos ou culturais (Durand, 2010, p. 94-95). A presença portuguesa só se efetivou no século XX e mesmo assim de modo bastante conflituoso, por meio de guerras contra os distintos reinos estabelecidos na ilha. Somente assim houve um processo de unificação administrativa e governamental que sustentou o esboço de um Estado nacional que não eliminou a diversidade étnica, cultural e linguística do país.

1 Um dos textos mais completos sobre a presença histórica da língua portuguesa em Timor-Leste até a ocupação indonésia está em Thomaz (2002).

2 Para um aprofundamento na história de Timor-Leste, recomenda-se a leitura de Durand (2010). 
O processo de independência timorense ocorreu no mesmo período das ex-colônias portuguesas na África, na década de 1970. Assim como nos países africanos colonizados por Portugal, a manutenção da língua portuguesa já era considerada um consenso entre os diversos partidos políticos timorenses, como a UDT e a Fretilin (dois dos principais partidos timorenses) (Forganes, 2002 210). Contudo, apesar da independência, uma guerra civil entre os dois grandes partidos políticos timorenses fragilizou a organização social e política do país, o que facilitou a entrada e o domínio do exército indonésio um mês após a declaração da independência. Sem mais interesses econômicos, Portugal não fez grandes esforços para salvaguardar a população que até pouco tempo estava sob o seu domínio e cuidado. Assim, Timor-Leste passou a ser mais um dos territórios indonésios, durante um considerável período (1975-1999).

Desse modo, se a presença lusitana começava a ser apagada pelo novo colonizador, com a língua portuguesa não seria diferente. Quase que imediatamente, o governo central indonésio não apenas proibiu o uso da língua portuguesa (mantida somente em missas e ritos da igreja católica), como ainda impôs a língua oficial do país (a bahasa indonésia). Além de apagar quase toda a marca da presença portuguesa no país, a Indonésia foi também responsável pelo extermínio de parte considerável da população timorense durante a sua governança, marcada pela repressão e violência.

A língua portuguesa, no entanto, não se manteve apenas nas liturgias católicas espalhadas por Dili ou outras cidades timorenses. Um outro fator, considerado fundamental para a persistência do português no país, foi o fato de a língua portuguesa ter sido adotada pela Resistência timorense, cravada tanto nas montanhas do país, na comunicação entre os pares, quanto às denúncias e apelos à comunidade internacional. A língua portuguesa é, portanto, tratada como um dos símbolos da resistência ao domínio indonésio, uma das marcas identitárias do timorense (ao lado da fé cristã) - fundamentais para assinalar a sua singularidade no contexto geopolítico em que se encontra. 
Mesmo com essa função renovada da língua portuguesa, os prejuízos causados durante o período indonésio foram bastante significativos. Dentre os absurdos provocados pelo regime militar indonésio durante a ocupação, podemos observar os riscos vividos constantemente pelos timorenses por meio do depoimento de D. Ana, professora timorense de língua portuguesa em 1975 (ano da invasão indonésia):

Muitos morreram porque eram professores de português, ou desapareceram depois da invasão indonésia. Eu mesma fiquei 24 anos sem lecionar. Tenho vergonha de falar um mau português, mas durante todos esses anos nós não tínhamos livros, revistas, radio, televisão, nada para praticar a língua. Eu esqueci muita coisa, é uma pena... (D. Ana apud FORGANES, 2002, p. 432).

Somente após uma grande pressão da comunidade internacional - em decorrência de um vídeo divulgado pelo jornalista Max Stahl em que jovens estudantes timorenses foram mortos pelo exército indonésio no cemitério de Santa Cruz -, o invasor indonésio aceitou a realização de um plebiscito organizado pelas Nações Unidas para que os timorenses escolhessem entre a independência do país ou a manutenção do território como parte da Indonésia. Após uma eleição tensa, a opção pela independência foi vencedora. Apesar de aparentemente o governo militar indonésio aceitar o resultado, houve um apoio não-oficial a milícias formadas por timorenses contrários ao resultado da consulta que, então, aproveitaram o clima político do país para literalmente queimar diversas cidades, prejudicar fortemente a infraestrutura do país e matar centenas de timorenses. Por conta do massacre, a ONU enviou suas tropas para pacificar imediatamente o país e passou a administrá-lo durante 3 anos, acontecimento único que ficou a cargo do brasileiro Sérgio Vieira de Melo, responsável pela transição administrativa necessária para devolver a autonomia política aos timorenses.

Depois de retomar sua independência em 2002, as autoridades timorenses decidiram estabelecer a língua portuguesa como língua oficial, 
ao lado do tétum ${ }^{3}$. Desde aquele momento, governo e sociedade timorenses têm buscado maneiras de difundir o uso da língua portuguesa em todas as esferas da vida social e nos diversos níveis de ensino escolar. Há, ainda, todo um esforço para registrar as inúmeras línguas timorenses e estabelecer uma gramática e um dicionário para cada uma delas.

Timor-Leste permanece com um mosaico linguístico composto, por um lado, pelas línguas locais (de dois ramos linguísticos distintos - austronésio e papua) e pelo tétum (língua franca, nacional e oficial) e, por outro, pelo português (enquanto língua oficial sendo reintroduzida), pelo inglês (língua global e também do vizinho Austrália) e pelo indonésio (língua de toda uma geração de timorenses - a chamada geração Timtim) ${ }^{4}$. Com isso, é quase inevitável não haver uma tensão linguística que opõe diferentes gerações: as mais novas hoje falam tétum e aprendem o português nas escolas, enquanto outra geração fala tétum e indonésio e a geração da resistência timorense, com mais de 40 anos, fala (ou compreende) português ou pelo menos já passou pela experiência do contato com essa língua (BRITO, 2013, pp. 83-84).

É nesse contexto plurilinguístico que o ensino de língua portuguesa se tornou obrigatório nas escolas timorenses e, nos últimos anos, na única universidade pública do país: a Universidade Nacional de Timor-Leste (UNTL). Contudo, os esforços do Estado timorense não são suficientes, por si só, para fazer a língua portuguesa ser uma língua usada por todos os cidadãos em situações variadas. Os auxílios de Portugal e do Brasil foram, e continuam a ser, imprescindíveis para auxiliar no processo de ensino da

3 É preciso, ainda, lembrar do papel exercido pelo linguista australiano Geoffrey Hull, cujo discurso proferido às lideranças timorenses foi essencial para a decisão de manter a língua portuguesa e do tétum como línguas oficiais do país naquele momento (Forganes, 2002).

4 Outro aspecto que merece destaque é a relação que se estabelece entre o tétum e o português, tal como apresentam Corte-Real e Brito (2018), mostrando que a realidade secular da paridade tétum-português é um traço cultural indispensável para a afirmação identitária timorense. 
língua portuguesa aos jovens timorenses, em todos os segmentos escolares do país.

O presente texto tem por objetivo refletir sobre como é possível ensinar em um contexto multilinguístico e multicultural como é TimorLeste. Assim, este trabalho visa a mostrar uma perspectiva da inserção da língua portuguesa no país asiático. Mais do que refletir sobre a formação de professores, é preciso pensar em como reintroduzir uma língua que ficou proibida por quase 25 anos e só pode ser utilizada de modo "clandestino" e "ilegal" pelo ponto de vista do dominador indonésio. Por isso, este texto está dividido em duas partes: a primeira se refere a experiências sobre o ensino da língua portuguesa em Timor-Leste no ano de 2001 (pouco depois da saída dos indonésios, durante o período de Administração Transitória das Nações Unidas) com um processo de seleção, capacitação e acompanhamento de 170 timorenses para atuarem como alfabetizadores da língua portuguesa; a segunda experiência foi desenvolvida ao longo de 2012, na UNTL, com jovens recém ingressantes na vida universitária, como a primeira geração que teria sido educada em português no país independente.

Apesar do caráter técnico de todo texto que se insere na pesquisa acadêmica, é inevitável não transparecer igualmente traços da vivência de cada um dos participantes dessas experiências. Em outras palavras, a apresentação dos métodos e dos recursos utilizados para o ensino da língua portuguesa em território timorense se mesclará com impressões mais pessoais sobre as relações sociais praticadas.

\section{Experiências de ensino de língua portuguesa em Timor-Leste: dois relatos}

A primeira experiência relatada nesta seção ocorreu em 2001, quando houve seleção e preparação de timorenses para, naquele momento da reconstrução histórica, atuarem como alfabetizadores de jovens e adultos em língua portuguesa. Poucos dos participantes tinham exercido 
funções ligadas ao ensino e muitos tinham pouco mais de quatro anos de escolaridade. A difusão da língua portuguesa em Timor-Leste revela-se tarefa hercúlea tendo em vista a precariedade material e de infraestrutura do país e da responsabilidade em relação à expectativa gerada, uma vez que, naquele momento pós-independência, a realidade timorense estava permeada por desafios, tais como: altas taxas de desemprego, condições habitacionais e de saúde precárias, formação profissional deficitária, entre outras questões. Do ponto de vista linguístico, parte significativa dos timorenses adultos trazia o português (língua oficial da nação independente) na memória e um forte comprometimento cidadão de estar presente nas transformações da vida social que recomeçava em Timor-Leste.

Antes de se trabalhar com a língua portuguesa em sala de aula, foi preciso uma compreensão do contexto e das condições efetivas da sociedade timorense. Assim, a primeira etapa (concomitante à necessária imersão na conjuntura sócio-histórico-cultural) consistiu no levantamento de dados relativos à fala e à escrita dos timorenses no contexto de uso do português. A partir dos dados, foi possível, então, observar quais elementos mereceriam maior atenção para tentar minimizar dificuldades dos timorenses no uso da língua portuguesa, tanto em sua modalidade oral como escrita. No momento de analisar as informações obtidas, procurou-se também utilizar o distrito de origem e a língua materna como variantes de influência para a produção linguística em português.

As análises realizadas nos mostraram, na produção oral, dificuldades de articulação de alguns fonemas. Por exemplo, a realização de consoante alveolar no lugar de palatal ('zanela', 'zesto', 'fuziu') e vice-versa ('faser', 'dizer'), além da desnasalização (como em 'dasar', 'laraza', 'apredemos').

Observou-se também como a língua materna interfere no uso de uma língua estrangeira escrita, como é o caso do português em Timor-Leste. Assim, viu-se fenômenos díspares como processos de monotongação ('maoria', 'desado'), desestruturação lexical ('clonisar', 'palavras') e o uso indevido de letras ('Indonezia', 'visavó'), que são presenças do tétum no momento 
do uso da língua portuguesa. Houve também uma frequência constante de troca de letras que pode representar o mesmo fonema ('brazileiros', 'corajem', 'eleisão'), supressão de letras e sílabas ('aprentar', 'granto') e processos de juntura ('aseguir', 'outravez') ou de segmentação ('a cima', 'em frentar', 'a onde') indevidas. Além disso, apareceram, com bastante frequência, ausências de reflexão verbal, concordância verbal, nominal e verbo-nominal, regência entre outros traços. A título de exemplo, alguns trechos recolhidos na ocasião são apresentados a seguir: "O povo Timor Leste fizeram uma eleição para ser independe (...)"; "Eu gosto muito aprender a ler a falar escrever a contar língua portuguesa"; "A língua portuguesa equecime [esqueci-me] alguns partes uma parte ainda lembro uma parte não me lembra"; "A língua portuguesa quando Portugal governar Timor os rapazes e os povos maior usaram".

Depois da análise dos dados e da seleção dos alfabetizadores, foi realizada a etapa de preparação dos encontros de capacitação dos selecionados. Essa fase focalizou, basicamente, o desenvolvimento das habilidades orais e escritas do uso da língua portuguesa pelos timorenses. Além das conversas informais realizadas dentro e fora do horário dedicado à capacitação, foram feitas também atividades dirigidas para a expressão oral (como leituras, travalínguas, canções, fala espontânea, entrevistas etc.) como forma de comprovar as dificuldades apontadas anteriormente, e principalmente como forma de conscientização das particularidades da fala produzida pelos professores timorenses (sempre tendo em vista que a norma do português utilizada é a europeia) e modos de adequação da pronúncia e da organização da fala.

Em relação à produção escrita, foram separados seis diferentes tipos textuais (dos mais cotidianos, como um relato do primeiro dia de aula e a tradução de um aviso em tétum, aos gêneros canônicos, como a narração, a descrição e a dissertação, passando, por fim, pelo poema) para mostrar as diferentes possibilidades de expressão escrita para os professores timorenses. Nesse sentido, a proposta se concilia com o que afirma Travaglia, quando reflete sobre gêneros (mas em outro contexto de ensino): 
Parece que o que deve ser feito é o desenvolvimento de habilidades linguístico-discursivas básicas, utilizando, para tal, conjuntos de gêneros que permitem o desenvolvimento dessas habilidades. Na escolha desses gêneros, a proposta é que se trabalhe com gêneros de circulação mais geral ou necessária na sociedade, independentemente de atividades profissionais que se venha a ter. ou seja, trabalharíamos com gêneros de comunidades discursivas mais abrangentes ou gêneros de circulação ampla na sociedade, independentemente da comunidade discursiva que o criou (TRAVAGLIA, 2010, p. 151).

Com o pouco tempo para desenvolver essas atividades (cerca de mês e meio), seria impossível solucionar muitos aspectos levantados no contato com os timorenses. De qualquer forma, foi possível mostrar-lhes particularidades da língua portuguesa, a existência de diversos usos e variedades dessa mesma língua e as diferenças (e relações) em relação às línguas de Timor-Leste.

A experiência apontou que é imprescindível a preocupação com a expressão linguística e é preciso conscientizar os usuários de que cada sistema linguístico (língua local, tétum e português) se estrutura diferentemente. Deste modo, a estrutura da língua portuguesa é diferente da tétum ou da bahasa indonésia e que as interferências são naturais e enriquecedoras. Além disso, não há como ter um ensino de língua eficaz sem estabelecer uma relação com a realidade cultural que a utiliza e que desconsidera a visão de mundo que a língua revela. Vimos essa questão como crucial no contexto timorense, dado que o processo de ensino de língua portuguesa será bilíngue (melhor seria dizer multilíngue): muitas vezes, as explicações dadas pelo alfabetizador terão de ser em tétum, em língua indonésia ou em uma das línguas locais.

Cabe, por fim, destacar a vontade de aprender dos timorenses e a consciência de seu papel cidadão na reconstrução do país. Além disso, a atuação pautou-se na perspectiva freireana de educar para a autonomia, objetivo primordial no processo de ensino-aprendizagem. Autonomia compreendida como "[...] um processo gradativo de amadurecimento, que ocorre durante toda a vida, propiciando ao indivíduo a capacidade de decidir 
e, ao mesmo tempo, de arcar com as consequências dessa decisão, assumindo, portanto, responsabilidades" (VASCONCELOS e BRITO, 2019, p. 49). A autonomia torna-se uma conquista construída a partir do desenvolvimento de outras habilidades, como a capacidade de interpretação do mundo e do outro e a capacidade de comunicação com o mundo e com o outro.

Pouco mais de dez anos separam uma experiência da outra. No decurso do tempo, seria preciso examinar quais as características linguísticas que permaneceram na língua portuguesa usada em Timor-Leste, quais seriam os novos fatos linguísticos que surgiram e quais se perderam no fio da história (além das motivações intrínsecas ao sistema linguístico ou às pressões sociais que muitas vezes levam às mudanças da forma).

Uma diferença fundamental entre as duas experiências deve ser destacada: foram dez meses de trabalho em solo timorense, no espaço institucional da Universidade, ao contrário da anterior que se desenvolver em pouco mais de um mês em meio. Contudo, mais tempo não significa melhores condições de trabalho, uma vez que as aulas de língua portuguesa se restringiam a um encontro semanal, de uma hora e meia, em turmas que ultrapassavam facilmente os sessenta estudantes em sala de aula.

Algumas dificuldades específicas parecem permanecer na variedade da língua portuguesa que se concretiza em Timor-Leste, quando temos por parâmetros as normas brasileira ou portuguesa. Por exemplo, a ausência de preposições e de marcas de concordância nominal, troca de letras, ausência de elementos coesivos, entre outros, foram algumas marcas diferenciais encontradas na escrita dos estudantes universitários timorenses. A título de exemplo, são mostrados abaixo trechos selecionados de redações produzidas a partir do tema "Meu distrito":

\footnotetext{
A minha Distrito tão pequena e mais linda tem montanha de Paicau, e tem ilha do Jaco o turista vai para visitar na minha Distrito";

"Timor-Leste têm muitas lugares na area turismo como; area brança, estatua de Cristo-Rei, Monomento de João Paulo II na Tasi-tolu e também outros lugares que antigamente os portuguêses fazerem no Timor-Leste
}

Confluência. Rio de Janeiro: Liceu Literário Português, n. 62, p. 150-173, jan.-jun. 2022 
como; Monomento de Lifau, Castilo de Maubara, eis prissão Antiga Balide e etc...";

"O Distrito de Baucau cheiar também pisinha, pouzada, aeroporto de Baucau"; "Aminha distrito Ermera que mencionado cada vez o distrito Ermera sempre alcanca objectivo o sistema politica para distribuição de proseso o produto de café na exportação de estrangeiro.

Defrontados com questões dessa natureza, revimos as expectativas em relação ao processo de ensino-aprendizagem da língua portuguesa pelos estudantes timorenses. O objetivo foi reformulado para, antes de tudo, sensibilizar o aluno para expressar-se em português, procurando minimizar o receio, a timidez e o medo de se comunicar em língua portuguesa. Desse modo, esperava-se despertar nos estudantes o prazer de usar a língua portuguesa e se fazer ser compreendido na comunicação diária. Por essa razão, foi necessário um conhecimento empírico do contexto social, linguístico e cultural timorense por meio de conversas com alunos e professores locais, momentos que produziam informações mais pessoais, como distrito de origem, língua materna, características familiares etc., mas também permitiam ter um contato mais próximo da realidade daquelas pessoas e, sobretudo, de suas histórias de vida.

Assim, o fundamento das aulas passou a ser o da língua em uso. Apesar da mescla entre as dificuldades de compreensão e da timidez, que prejudicava a expressão dos alunos, aos poucos, eles foram dominando a dinâmica dialogada das aulas, com perguntas e respostas, e perceberam que essa foi uma oportunidade de eles a utilizarem em sala de aula. Entendemos também que deixar o ambiente o mais confortável possível para o estudante timorense facilitou esse contato e a melhora no ritmo das aulas.

Munido dessa informação, o primeiro gesto foi discutir e desenvolver a noção linguística de tempo (passado, presente e futuro) com os estudantes timorenses para, em seguida, mostrar como são utilizados os tempos verbais em língua portuguesa (destacando os tempos mais utilizados). No final do primeiro semestre, foi elaborado um material específico sobre conjugação 
verbal, a partir da morfologia dos verbos regulares em suas três bases (-ar, -er, -ir) e uma tabela com os principais verbos irregulares da língua portuguesa.

No entanto, as aulas não foram centradas em aspectos gramaticais do português, mesmo porque desde há muito não é possível confundir aulas de língua com aulas de gramática (Bechara, 2006; Possenti, 1996). Neste ponto, cabe retomar Evanildo Bechara, pois ele antecipava reflexões sobre o papel da gramática normativa, sua função na sala de aula e na conquista da cidadania e sobre a importância de uma aplicação consciente das teorias linguísticas no ensino de Língua Portuguesa. Para o autor:

[...] haverá opressão em "impor", indistintamente, tanto a língua funcional da modalidade culta a todas as situações de uso da linguagem, como a língua funcional da modalidade familiar ou coloquial, nas mesmas circunstâncias, a todas as situações de uso da linguagem, pois que ambas as atitudes não recobrem a complexa e rica visão da língua como fator de manifestação da liberdade de expressão do homem. Por outro lado, haverá "liberdade" quando se entender que uma língua histórica não é um sistema homogêneo e unitário, mas um diassistema, que abarca diversas realidades diatópicas (isto é, a diversidade de dialetos regionais), diastráticas (isto é, a diversidade de nível social) e diafásicas (isto é, a diversidade de estilos de língua), e que cada porção da comunidade linguística realmente possui de direito sua língua funcional, que resulta de uma técnica histórica específica (BECHARA, 2006, p. 14-15).

Uma opção que se impôs foi a de partir de elementos básicos, tal como são ensinados nas aulas de língua estrangeira. Foram feitos exercícios que simulavam formas de se apresentar e de como conhecer alguém em língua portuguesa. Eram exercícios realizados em dupla ou em trio e os alunos pareciam se divertir bastante. Além disso, foram feitas apresentações em grupo, a partir de propostas como "contar uma história de seu distrito", "o que gosto de fazer no final de semana", "a história de minha família", "meu melhor amigo" etc. Esses temas também foram usados para exercitar a escrita em português com a realização de redações como atividade extraclasse 
(com as devidas orientações de organização textual). A título de exemplo, apresentamos duas redações com o tema "meu distrito", que consideramos paradigmáticas do modo como uma parte considerável de estudantes timorenses escrevem:

(Redação 1) Composição sobre a minha de "ERMERA"

O Distrito de Ermera tem muitas riquezas como: café, cameli, Marmar, sandalo etc.

O Distrito de Ermera dividiu em cinco subdistritos como Hatolia, Ermera, Letefoho, Railaes, Atsobe em Timor Leste. O distrito de Ermera conhecido no mundo. porque tem varios de recursos humanos, e também produtos de Distrito de Ermera como Tais milho, arroz, larancas etc.

Até aqui uma composição sobre o meu distrito Ermera e muito Obrigado.

(Redação 2) Redação sobre o meu distrito.

O meu distrito fica na parte leste da capital de Dilí chama-se distrito Manatuto e tem seis (6) sub-distrito. Eu sintio que é bonita, porque tem várias áreas interessante como: Nossa Senhora de Aitara que localizada no sub-distrito de Soibada e outra é gruta de Santo Antonio, Be-heda Manatuto e outra.

Para mim eu quero estudar muito para dezenvolve e servi a nossa nação e o mesmo distrito.

O minha redação última é se você quer visita para nossa distrito, sinto que você senti fica contente e feliz para sempre.

Obrigado!

(NS)

Se tomarmos emprestado o conceito de coerência, tal como propõe Koch e Travaglia (2006), podemos dizer que a coerência se baseia no sentido unitário global do texto, assim como pela continuidade de significações dos conhecimentos ativados pelas expressões do texto, em uma organização hierarquizada de uma determinada produção textual. 
Apesar dos problemas de ordem gramatical que os fragmentos acima apresentam, os trechos mais longos apresentam uma coerência semântica (temática e figurativa) que se sustenta por meio da proposta de redação que fora realizada com alguns alunos. Desse modo, em nenhum momento houve um afastamento do tema proposto. Além disso, os alunos têm a oportunidade de, por meio de sua produção textual, apresentar o seu conhecimento de mundo veiculado pela língua portuguesa.

Ademais, como afirma Possenti (1996), mais importante do que se preocupar, em demasia, com elementos gramaticais, importa sim fazer o aluno aprender diferentes tipos de texto. Os recorrentes "equívocos" gramaticais podem ser trabalhados conforme a necessidade da turma e, em seu limite, com cada aluno individualmente. De qualquer forma, as redações dos alunos timorenses tinham como característica a falta de hierarquia dos subtemas desenvolvidos a partir do tema central proposto. Além disso, apresentavam também problemas em relação ao tipo textual proposto, que era mais voltado para uma descrição das características do distrito de onde viera, mas que resultou, muitas vezes, em um texto mais simples, muitas vezes feito com itens para apresentar as peculiaridades da região de origem de cada estudante.

Os exercícios de diálogo simulado e as aulas de uso do verbo foram usados também para se tentar criar uma individualidade entre os estudantes, que no começo do semestre estavam imbuídos ainda de um discurso coletivo de auxílio ao país. Assim, por exemplo, recorremos ao ensino e ao uso de verbos como "querer", "gostar", "pensar", "crer", pois serviram para iniciar um processo de individuação entre os estudantes, que vieram de um contexto escolar básico no qual a individualidade não era incentivada para que se ressaltasse a importância da coletividade para a nação.

Outro recurso com resultados bastante satisfatórios foi o uso de lendas timorenses (encontradas na internet) para exercitar a leitura e a compreensão dos textos. Esse ponto foi importante para conhecer um pouco mais a cultura timorense e tentar valorizá-la junto aos estudantes, uma vez que havia certo constrangimento quando lendas eram comentadas em sala de aula. Outro 
material de apoio utilizado nas aulas foi a música brasileira, preferencialmente a música sertaneja. O sucesso desse estilo musical em Timor-Leste parece estar ligado, por um lado, à história narrada pelas músicas que geralmente falam de amor, de família ou ainda da relação campo-cidade e, por outro, pelo fato de elas serem cantadas em um ritmo mais lento, com vogais mais alongadas, que parece auxiliar na compreensão do aluno timorense.

Ao final de nossa experiência com estudantes da UNTL, foi perceptível a sensível melhora no uso da língua portuguesa por parte dos alunos. Evidentemente, essa melhoria é ainda pequena diante do que é desejável para um falante autônomo e competente em língua portuguesa como língua estrangeira. De qualquer forma, com a continuidade do aprendizado e a dedicação que os alunos têm, é possível observar que estudantes timorenses já atingiram um patamar adequado de competência e de desempenho linguísticos ao final de sua graduação pelo contato que continuamos a manter por meio das redes sociais com alguns deles.

\section{Ensinar português: uma reflexão a partir das vivências}

Em anos mais recentes, uma discussão envolvendo grandes personalidades do mundo político timorense colocou em dúvida o ensino das línguas oficiais (português e tétum) para crianças em fase de alfabetização. Aqueles que questionavam tal política de educação linguística justificavam suas críticas no interesse pelo desenvolvimento do ensino das línguas locais existentes em Timor-Leste, o que faria com o ensino do português entrasse apenas em anos subsequentes, e não nos primeiros anos da vida escolar (do pré-escolar até o $3^{\circ}$ ciclo).

Para além dos discursos conspiratórios (segundo os quais haveria uma intenção obscura de se enfraquecer o português para, assim, ser mais fácil implantar o inglês como língua oficial), gostaríamos de propor um outro caminho para o debate, que envolve a formação de professores, políticas 
públicas e a experiência direta no campo de estudo: a sala de aula em TimorLeste. Mesmo com todas as dificuldades de implementação e de condições de ensino e de uso, a língua portuguesa permanece entre as línguas utilizadas e necessárias em Timor-Leste.

Entendemos ser preciso não apenas discutir sobre o ensino das línguas locais, o que requer, antes de tudo, pesquisas de campo para se criar gramáticas e dicionários adequados a um processo de inclusão de tais línguas no plano da escrita. Além disso, qualquer tentativa de se estabelecer um padrão para o ensino da língua portuguesa deveria seguir também estudos que foram realizados por especialistas na área.

Por exemplo o trabalho de Guimarães (2018) chama a atenção para a necessidade de distinção entre a oralidade e a escrita. Dentro de cada um dos aspectos da língua, há ainda outras possibilidades de entendimento sobre o que ensinar. No caso da oralidade, o que se deve ensinar? Gêneros mais formais ou aqueles que podem ser funcionalmente mais apropriados para as atividades cotidianas? Nesse caso, como recortar o que é mais apropriado para o aluno? Entendemos que é preciso também compreender as condições de vida dos alunos timorenses em sua diversidade local, tanto de cada distrito como também em relação aos sukos ${ }^{5}$, para se planejar atividades para as quais a língua portuguesa pode ser útil aos alunos e à sua comunidade.

No caso da escrita, é preciso também refletir sobre os gêneros a serem transmitidos em sala de aula. Para isso, é preciso também observar o perfil do aluno. Na pesquisa feita por Guimarães (2018), o perfil era de jovens professores, o que envolve suprir uma certa falta de conhecimento em relação à atividade profissional que eles exercem. No caso dos relatos deste trabalho, o foco era, primeiramente, professores que ensinariam os elementos mais básicos da língua portuguesa, e na outra experiência, eram jovens alunos ingressantes em diferentes cursos da UNTL. Nesse sentido, pensar tanto no

5 Menor unidade administrativa em Timor-Leste. Seria algo próximo à nossa noção ocidental de aldeia.

Confluência. Rio de Janeiro: Liceu Literário Português, n. 62, p. 150-173, jan.-jun. 2022 
perfil como no nível escolar a ser ensinado deve ser uma prerrogativa para antes de se entrar em sala de aula, pois assim se evita um impacto em relação à realidade do professor e também dos alunos em questão, diminuindo, assim, um dos problemas identificados a partir de uma de nossas experiências: a falta de contato e, sobretudo, de prática no uso da língua portuguesa, tanto em seu registro oral como na comunicação escrita (leitura e produção de textos).

Ademais, entendemos que também deve ser levado em consideração as condições econômicas e políticas vigentes no país no momento em que se cria um plano nacional de introdução e implementação da língua portuguesa. Um plano nacional de educação timorense, que reconhece o contexto multilinguístico do país leva a uma outra postura, distinta daquele que foca apenas nas línguas oficiais:

As diretrizes curriculares atuais de Timor-Leste reconhecem a multiplicidade linguística presente no país e apontam a importância da(s) língua(s) que o aluno domina no processo de aquisição/desenvolvimento de outras, como o português. Sendo assim, as línguas que integram o repertório linguístico dos alunos participam desse processo, em um plano progressivo - da pré-escola, com a utilização da língua tétum e das demais línguas maternas, 3 ao $3^{\circ}$ ciclo do ensino básico, quando a orientação é que o ensino seja realizado nas línguas oficiais do país, com a carga horária da disciplina de língua portuguesa superior à da disciplina da língua tétum. Entretanto, ainda há, em Timor-Leste, uma enorme distância entre aquilo que preconizam os documentos que prescrevem as atividades pedagógicas no ensino básico e a realidade em que atuam os docentes nos ambientes de ensino. Os motivos para tal distanciamento são vários: sobreposição de orientações, tendo em vista o caráter e a urgência de constantes mudanças visando à melhoria da educação timorense; desconhecimento dos docentes em relação a essas orientações (seja pela sobreposição de orientações ou por deficit na formação inicial e continuada); utilização de documentos criados em contextos sem, muitas vezes, considerar a realidade linguística timorense; 4 e, além disso, fatores externos, que interferem sobremaneira no desenvolvimento do processo de ensino e aprendizagem (infraestrutura inadequada, número elevado de alunos nas salas de aula etc.) (GUIMARÃES, 2018, p. 702).

Confluência. Rio de Janeiro: Liceu Literário Português, n. 62, p. 150-173, jan.-jun. 2022 
A partir do reconhecimento e da discursivização legal da situação linguística do país, algumas perguntas devem ser feitas para orientarem as políticas linguísticas: que padrão do português deve ser ensinado? Devemos igualmente olhar para as especificidades de um português timorense ainda em formação (e não completamente estabelecido, como alguns estudos querem fazer parecer como algo já dado?). Assim, antes mesmo de se usar uma teoria, entendemos que é preciso conhecer diretamente as condições de trabalho e a realidade dos estudantes timorenses. Não há uma razão justificável que separe a teoria da realidade do aluno. No caso de Timor-Leste, esta questão nos parece ainda mais premente, na medida em que é preciso reconhecer as dificuldades que um projeto de reintrodução de uma língua já considerada oficial pode provocar, além dos conhecidos impedimentos e resistências que ocorrem em um país que é foco de interesse de potências globais e locais, seja pela sua localização geopolítica, seja por causa da exploração de petróleo.

Desse modo, é preciso reconhecer as dificuldades de escrita em língua portuguesa por parte dos timorenses. Mas não se deve limitar a abordagem a uma mera descrição de fatos linguísticos (como se fosse um almanaque de curiosidades). É preciso ainda saber as especificidades do conhecimento que estes alunos trazem (como o ensino do português baseado apenas na gramática, sem qualquer tipo de liberdade ou de respeito à autonomia do aluno no uso da língua), nas exigências culturais (como o medo de errar e da vergonha de errar) e das condições mais básicas de vida desses alunos (falta de moradia, dinheiro, má alimentação, entre tantos outros fatores que fogem do escopo do trabalho docente). Também devemos combater alguns mitos relacionados à relação entre língua portuguesa e os timorenses, assim como as dificuldades reais e materiais existentes no país:

São eles: a defasagem na alfabetização em língua portuguesa; o pouco acesso a livros (devido ao alto valor comercial, podemos considera-los objetos de luxo); as crenças de que a língua portuguesa é difícil e de que timorense não sabe falar português; as raras livrarias; as escassas bibliotecas; o pouco contato dos estudantes com outras variantes da 
língua portuguesa; a língua como forma de ascensão social e profissional (futura exclusão social); a limitada difusão da cultura escrita (que tem por consequência, entre outas, o insuficiente acesso a diversificados gêneros textuais; e a ausência de hábitos de leitura (DINIZ e SILVA 2013:18).

O estudo de Diniz e Silva (2013) tem o mérito de mostrar as crenças existentes em torno da língua portuguesa em Timor-Leste. De um modo geral, as autoras tratam da imagem que os timorenses têm em relação às dificuldades de aprendizagem. Contudo, precisamos também levar em consideração que as condições de aprendizagem das línguas locais para os timorenses são bastante diversas da aprendizagem da língua portuguesa em Timor-Leste. Assim, os timorenses falam, geralmente, mais de uma língua, mas ela é aprendida no cotidiano, de modo espontâneo, desde a infância. Não há um ensino formal das línguas, mas sim um aprendizado a partir do que as crianças têm contato, como os estudos de aquisição de linguagem nos mostram.

Talvez haja aí uma explicação para o sentimento de dificuldade para se aprender a língua portuguesa, além das conhecidas diferenças estruturais existentes entre tétum e português e que já foram mencionadas neste trabalho. Assim, as autoras mencionam três crenças recorrentes nos discursos de estudantes timorenses. A primeira é de que o português é difícil porque tem muitos verbos e preposições. A segunda crença é de que eles não sabem português e, por fim, há uma crença de que saber português é importante para o futuro.

É necessário observar também como os diferentes países presentes por meio de projetos de cooperação estão, efetivamente ou não, auxiliando na reintrodução da língua portuguesa em Timor-Leste. Como observa Carioca (2006):

Embora esteja em execução o Projeto de Reintrodução da Língua Portuguesa em Timor-Leste (PRLP), da responsabilidade do Instituto Português de Apoio ao Desenvolvimento (IPAD), existem muitas dificuldades no que diz respeito ao ensino da língua, sendo a maior 
delas a falta de preparação geral em relação ao ensino no país, pois não houve preocupação com o uso de estratégias específicas e adequadas ao contexto situacional timorense, ocorrendo praticamente apenas, nos primeiros anos, a utilização das metodologias, estratégias e materiais que eram usados em Portugal (CARIOCA, 2016, p. 433-434).

Carioca (2016) mostra a necessidade de se conhecer a função social das línguas em Timor-Leste. Seu estudo visa a compreender como os timorenses se relacionam com as diversas línguas e as utilizam de modo distinto, na medida em que os diferentes contextos e situações mobilizam diferentes saberes. Por isso, superar as barreiras entre a nossa cultura e a cultura timorense também deve ser um trabalho para reconhecermos nossos preconceitos e trabalharmos para superá-los. Além disso, podemos também pensar em contextos bilíngues e multilíngues, em que a(s) língua(s) materna(s) influenciam e interferem no aprendizado de uma nova língua, como é o caso da língua portuguesa no contexto timorense.

Por isso, seguimos o educador Paulo Freire (2011) em relação ao ensino da língua: "A leitura do mundo precede a leitura da palavra". Entender como o outro lê/percepciona seu mundo é um ponto de partida para, então, se buscar meios teóricos e práticos para se chegar a um ensinamento efetivo, que respeita as especificidades locais, mas visa a um padrão global no qual a sociedade timorense pode, então, se beneficiar do uso da língua portuguesa como uma língua de contato internacional.

Com isso, não estamos renegando a importância da teoria, nem de temas educacionais ligados ao ensino da língua, como o gênero e o letramento. Contudo, questionamos a validade de tal abordagem em um momento inicial, na medida em que ela pode, de um lado, revelar um distanciamento em relação às especificidades locais (culturais, econômicas, sociais etc.) e, de outro, por resvalar em uma postura que não difere, em muito, de um colonialismo, se não linguístico, ao menos epistemológico.

Sem querer trazer respostas prontas e definitivas, nosso desejo é mostrar que a reintrodução de uma língua é um movimento que envolve diferentes 
instâncias de poder, mobiliza distintos interesses econômicos, sociais e políticos, assim como saberes que não se limitam a poucas áreas do conhecimento. De qualquer forma, parece-nos que um primeiro passo é escutar aqueles que têm o maior interesse nisso tudo: os próprios cidadãos timorenses.

\section{Conclusão}

Apesar de todas as tensões presentes nas discussões sobre qual a língua que deve predominar em Timor-Leste no futuro, vale a pena ressaltar que, mesmo depois de grandes experiências violentas, o povo timorense apresenta provas de que a tolerância parece ser um dos traços que o caracteriza. Afinal, o português, o inglês, o tétum, a língua indonésia e as línguas locais coexistem no mesmo espaço geográfico e social em Timor-Leste, utilizados em diferentes contextos e situações. Sem dúvida, um dos fatores de unidade do país é a difusão de uma cultura luso-timorense - o que possibilita, como exposto aqui, a presença de docentes brasileiros auxiliando na alfabetização e na formação de jovens e adultos; de professores portugueses trabalhando com o ensino de língua portuguesa para a educação básica; de profissionais ligados às áreas social, técnica e educacional proveniente dos diferentes países lusófonos. Todos falantes do português, mas carregando consigo a diversidade dos usos que o sistema propicia, concretizando na vivência cotidiana a mistura de sotaques, vocábulos, construções do muito que nossa língua comum abarca.

Se a ideia de uma língua única não passa de uma utopia (criada pelo menos desde o século XVIII pelos românticos), o que se deve celebrar em Timor-Leste é a manutenção de um espaço de encontro com o diverso e com o estranho, com o mesmo, com o (re)conhecido e com o outro mais distante. Essa característica mostra, assim, que é possível viver sem eliminar o outro, ideia que atravessa o discurso de Geoffrey Hull, linguista australiano, defensor da oficialização da língua portuguesa no momento em que o seu país de origem realizava uma grande pressão pela adoção do inglês pelos timorenses: 
Um programa linguístico inclusivo é o único remédio contra tendências políticas culturalmente contraproducentes que pretendem excluir uma ou outra língua. O que de verdade me parece importante é estabelecer as prioridades justas, baseadas em factos culturais, prioridades estas que estão voltadas para o futuro, mas que também não se esquecem do passado (HULL, 2001, p. 53).

Entendemos que o desafio timorense é articular passado e o presente, as tradições locais e a necessidade de dialogar com o exterior em um mundo globalizado (e permeado por diversas línguas) para que se respeite e valorize o que torna Timor-Leste um país único, mas sem desprezar o que ele pode aproveitar em termos linguísticos, econômicos e culturais para melhorar as condições de vida de sua população. Sem maniqueísmos, entendemos que a saída pela diversidade possui muito mais vantagens do que se buscar elementos que definam e, pior, solidifiquem uma identidade única da população timorense que, desde antes da chegada dos portugueses, já se mostrava bastante diversa em suas línguas e tradições.

Assim, o ensino da língua portuguesa passa pela articulação dessas distintas tensões. Cremos que elas não serão superadas, na medida em que um regime democrático não visa a suprimir divergências, mas administrá-las da melhor forma possível. No caso da língua portuguesa, sua reintrodução deve visar a uma manutenção estável em camada considerável da população timorense, sempre respeitando a diversidade linguística e as especificidades do português praticado em Timor-Leste.

\section{Referências bibliográficas}

BECHARA, Evanildo. Ensino da gramática. Opressão? Liberdade?. São Paulo: Editora Ática, 2006.

BRITO, Regina Helena Pires de. Língua e identidade no universo da Lusofonia - aspectos de Timor-Leste e Moçambique. São Paulo: Terracota, 2013. 
CARIOCA, Claudia Ramos. As funções sociais da língua e as políticas de difusão do Português no Timor-Leste. D.E.L.T.A., 32(2): 427-447, 2016. https://doi.org/10.1590/0102-4450412561118873818.

CORTE-REAL, Benjamim de Araújo; BRITO, Regina Helena Pires de. East Timor, Portuguese and Tetum: A Necessary Coexistence. In: Zanal, Sovon; Figueiredo, Arizangela; Cavalcante, Marcia (Eds.) A Língua Portuguesa na Índia e em outras Terras. New Delhi: Adroit Publishers, 2018.

DURAND, Frederic. História de Timor-Leste - da pré-história à actualidade. Lisboa: Lidel, 2010.

DINIZ, Izabel Cristina Silva; SILVA, Luana Fabrícia Correia. Língua Portuguesa em Timor Leste: contexto de ensino e crenças sobre aprendizagem. Revista Multidisciplinar Acadêmica Vozes dos Vales, 2(4): 1-20, 2013.

FORGANES, Roseli. Queimado queimado, mas agora nosso! Timor: das cinzas à liberdade. São Paulo: Labortexto Editorial, 2002.

FREIRE, Paulo. A Importância do Ato de Ler - em três artigos que se completam. São Paulo: Cortez Editora \& Autores Associados, 2011.

GUIMARÃES, Joice Eloi. Formação docente em Timor-Leste: prática e reflexão sobre gêneros discursivos e ensino. Revista Brasileira de Estudos Pedagógicos, 99(253): 700-713, 2018. http://dx.doi.org/10.24109/2176-6681. rbep. 99 i 252.3650

HULL, Geoffrey. Identidade, língua e política educacional. Lisboa: Instituto Camões, 2001.

KOCH, Ingedore Villaça; TRAVAGLIA, Luiz Carlos. A coerência textual. São Paulo: Editora Contexto, 2006.

POSSENTI, Sírio. Por que (não) ensinar gramática na escola. Campinas: Mercado das Letras, 1996. 
THOMAZ, L. F. F. R. Babel Loro Sa'e - O problema linguístico de TimorLeste. Lisboa: Instituto Camões, 2002.

TRAVAGLIA, Luiz Carlos. Comunidades discursivas, gêneros e ensino. In: N. B. BASTOS (org). Língua Portuguesa: cultura e identidade nacional. São Paulo: EDUC, 2010.

VASCONCELOS, Maria Lúcia; BRITO, Regina Helena Pires de. Conceitos de educação em Paulo Freire: glossário. Petrópolis, RJ: Vozes; São Paulo, SP: Mack Pesquisa, 2019. 